\title{
Association of Surgical Hematoma Evacuation vs Conservative Treatment with Functional Outcome in Patients With Cerebellar Intracerebral Hemorrhage
}

\author{
Haili WANG ${ }^{1}$, Lun DONG ${ }^{2}$, Yingzhu $\mathrm{CHEN}^{3}$, Jun ZHANG ${ }^{1}$ \\ 'Dalian Medical University, Department of Clinical Medicine, Dalian, China \\ ${ }^{2}$ Clinical Medical College of Yangzhou University, Department of Neurosurgery, Yangzhou, China \\ ${ }^{3}$ Clinical Medical College of Yangzhou University, Department of Neurology, Yangzhou, China
}

Corresponding author: Jun ZHANG doctorzhang_0221@163.com

To the Editor;

$\mathrm{W}$ e have carefully read the study by Kuramatsu et al. on "Association of Surgical Hematoma Evacuation vs Conservative Treatment with Functional Outcome in Patients With Cerebellar Intracerebral Hemorrhage" (2). The incidence of cerebellar intracerebral hemorrhage $(\mathrm{ClH})$ approaches $5-10 \%$ of all intracerebral hematomas. $\mathrm{ClH}$ is characterized by elevated intracranial pressure, acute onset of incoordination (vertigo and ataxia), or both (4). Clinical presentations vary from headache and dizziness to rapid deterioration of consciousness and coma in severe cases (1). Fortunately, we have had the opportunity to read this study of clear guiding significance. The fact is to select an operative indication in patients with $\mathrm{ClH}$ is a long-standing problem that plagues neurosurgery and neurologists. If the surgical pointer could be further clarified, patients with $\mathrm{ClH}$ might have a clearer shunt and treatment protocol (whether the patient shall undergo surgical hematoma evacuation or conservative treatment). Consequently, we are very interested in this study.

Although we have learned a lot from this study, the following issues seem to require exploration by relevant authors of the study and future researchers. First: Compared with conservative treatment, how safe are adverse events such as rebleeding, reoperation, intracranial infection, wound infection, lung infection, and urinary tract infection after surgical hematoma removal? Second: Compared with conservative treatment, does surgery increase the use of pain killers and / or sedatives and increase the incidence of anesthetic-related complications? Third: Is the location of hematoma in an important functional area of the cerebellum and surrounding brain tissue? Does this issue require urgent subgroup analysis? Is it neglecting this issue that leads to a negative conclusion? Fourth: Does the patient still have bleeding in other important areas of brain function other than the cerebellum? This can be a significant confounding factor. Fifth: Compared with conservative treatment, does surgery increase the patient's medical expenses, family and social burden? This issue is worth exploring in future study. Sixth: Study has reported a certain degree of positive correlation between different hematoma shapes (specific surface area) and the degree of cerebral edema (3). Therefore, the relationship between the specific surface area of $\mathrm{ClH}$ and operative indication is worthy of further study. Seventh: Differences in surgical precision between different neurosurgeons are usually inevitable. This may be one of the confounding factors in the study. If conditions permit, subgroup analysis of patients from different surgeon groups may be an effective way to weaken this confounding factor. In addition, we are expecting brain hematoma removal robots to join the study. Will the results be reversed by then?

In conclusion, we are very grateful for the study by Kuramatsu et al. (2), and hope that the authors can discuss some of the aforementioned issues.

\section{REFERENCES}

1. Dahdaleh NS, Dlouhy BJ, Viljoen SV, Capuano AW, Kung DK, Torner JC, Hasan DM, Howard MA 3rd: Clinical and radiographic predictors of neurological outcome following posterior fossa decompression for spontaneous cerebellar hemorrhage. J Clin Neurosci 19:1236-1241, 2012
Haili WANG (1) : 0000-0001-9614-2158 Lun DONG : 0000-0002-8150-2787
Yingzhu CHEN (D) : 0000-0002-2110-236X

Jun ZHANG (1) : 0000-0002-7869-2807 
Wang H. et al: Cerebellar Intracerebral Hemorrhage

2. Kuramatsu JB, Biffi A, Gerner ST, Sembill JA, Sprügel MI, Leasure A, Sansing L, Matouk C, Falcone GJ, Endres M, Haeusler KG, Sobesky J, Schurig J, Zweynert S, Bauer M, Vajkoczy P, Ringleb PA, Purrucker J, Rizos T, Volkmann J, Müllges W, Kraft P, Schubert AL, Erbguth F, Nueckel M, Schellinger PD, Glahn J, Knappe UJ, Fink GR, Dohmen C, Stetefeld H, Fisse AL, Minnerup J, Hagemann G, Rakers F, Reichmann H, Schneider H, Rahmig J, Ludolph AC, Stösser $\mathrm{S}$, Neugebauer H, Röther J, Michels P, Schwarz M, Reimann G, Bäzner H, Schwert H, Claßen J, Michalski D, Grau A, Palm F, Urbanek C, Wöhrle JC, Alshammari F, Horn M, Bahner D, Witte OW, Günther A, Hamann GF, Hagen M, Roeder SS, Lücking H, Dörfler A, Testai FD, Woo D, Schwab S, Sheth KN, Huttner HB: Association of surgical hematoma evacuation vs conservative treatment with functional outcome in patients with cerebellar intracerebral hemorrhage. JAMA 322(14):13921403, 2019
3. Sprügel MI, Kuramatsu JB, Volbers B, Gerner ST, Sembill JA, Madžar D, Bobinger T, Kölbl K, Hoelter P, Lücking H, Dörfler A, Schwab S, Huttner HB: Perihemorrhagic edema Revisiting hematoma volume, location, and surface. Neurology 93(12):112, 2019

4. Tewari MK, Tripathi M, Sharma RR, Mishra GP, Lad SD: Surgical management of moderate sized spontaneous cerebellar hematomas: Role of intracranial pressure monitoring. Turk Neurosurg 25(5):712-720, 2015 